Polymer Journal, Vol. 39, No. 12, pp. 1360-1364 (2007)

(C) 2007 The Society of Polymer Science, Japan

\title{
Network Formation of Interlocked Copolymer Obtained from Copolymerization of 1,2-Dithiane and Lipoic Acid by Metal Salt
}

\author{
Taku YAMANAKA and Kiyoshi ENDO ${ }^{\dagger}$ \\ Department of Applied Chemistry \& Bioengineering, Graduate School of Engineering, Osaka City University, \\ Sugimoto, Sumiyoshi-ku, Osaka 558-8585, Japan
}

(Received June 6, 2007; Accepted September 8, 2007; Published October 23, 2007)

\begin{abstract}
Network formation of interlocked copolymer obtained from the thermal ring-opening copolymerization of 1,2-dithiane (DT) and liopic acid (LPA) was investigated by the reaction of the poly(LPA-co-DT) and $\mathrm{Zn}$ (acetate $)_{2}$. From the IR spectra of the reaction products, the reaction was induced readily to make a enough high degree of cross-linking in which the cross-linking points are polycatenane using a bifunctional metal salts by effective an ionomeric network. The cross-linking reaction of the precursor copolymer gave more thermo-stable product by the formation of the enough high degree of cross-linking structure. [doi:10.1295/polymj.PJ2007069]

KEY WORDS Network Formation / Interlocked Copolymer / Copolymerization / 1,2-Dithiane / Lipoic Acid / Zn(acetate $)_{2} /$ Ionomeric Bonding /
\end{abstract}

Macromolecules comprising single and multiple cyclic polymer units have been synthesized as novel molecular assemblies, and they have also gained an interest due to their unique properties which are different from linear and branched polymers. ${ }^{1-7}$ Recently, many topological molecules such as rotaxanes and catenanes have been synthesized with a high efficiency. ${ }^{8}$ Since an intramolecular ring closing after the chain penetrates the other ring molecules should be induced, a synthesis of polymer containing a polycatenane structure seems to be very difficult. Nevertheless, we found a convenient synthesis of polycatenane polymer from the bulk polymerization of cyclic disulfides such as 1,2-dithiane (DT) without any initiators. ${ }^{9-11}$ The polymer was confirmed to contain a polycatenane structure (Scheme 1) from the characterizations of the polymer such as thermal and physical properties of the polymers. The polymer consisted of about 60 numbers of the non-interlocked cyclic polymer of DT, but the polymer dissolves in organic solvent such as $\mathrm{CHCl}_{3}$ and THF even though it is hardly soluble in the organic solvents. This may be due to that the molecular weight of the polycatenane polymer is not large enough to reach gel point.

Ito et al. reported a novel type of topological gel consisting of polyoxyethylene and bi- or tri-functional cyclodextrin, and they called this gel as "ring moving gel." 12 This gel is different from generally chemical and physical gels, and it showed superior physical properties. Tezuka et al. reported that the copolymerization's of vinyl monomers with macromonomer having a large cyclic part as the side chains gave the new type of topological gel copolymer that the main chains penetrated the large cyclic parts of the side chains. ${ }^{13}$ Although a synthesis of poly[n]catenane has been reported, ${ }^{14}$ a polycatenane network were not synthesized to our knowledge.

Previously, we reported the synthesis of a copolymer obtained from the copolymerization of DT and liopic acid (LPA) with a carboxyl group in the side chain. The structure of the copolymer was assumed to be polycatenene structure as well as the poly(DT), which is shown in Scheme $1 .{ }^{15}$ This copolymer is expected to make a novel network structure using a bifunctional metal salts and the attached acid groups to the polycatenane structure. Such network structure may provide unique physical properties. In this article, we report on a network formation reaction between $\mathrm{Zn}$ (acetate) $)_{2}$ and the acid group of the side chain in the interlocked copolymer obtained from a thermal copolymerization of DT and LPA.

\section{EXPERIMENTAL}

\section{Materials}

1,2-dithiane (DT) was synthesized as described in the previous paper, ${ }^{15}$ and purified by recrystallization from methanol at several times to remove completely BDT after fractional distillation. The purity of DT determined by HPLC was estimated to be $>99.9 \%$. Commercially available Lipoic acid (LPA, Tokyo Chemical Industry Co., Ltd.) was used after purified by recrystallization from cyclohexane. Other reagents and solvents were purified by conventional methods.

\section{Synthesis of 1,2-Dithiane}

1,2-dithiane (DT) was synthesized from BDT according to the following procedure. ${ }^{16}$ Concentrated

${ }^{\dagger}$ To whom correspondence should be addressed (Tel: +81-6-6605-2697, Fax: +81-6-6605-2697, E-mail: endo@a-chem.eng.osaka-cu.ac.jp). 


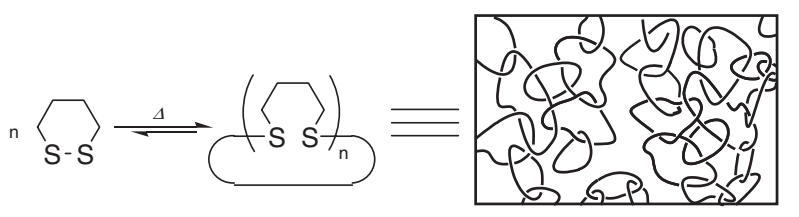

Scheme 1. Polymerization of DT and model of the polycatenane.

hydrochloric acid $(7 \mathrm{ml})$ was added to dimethyl sulfoxide solution $(200 \mathrm{ml})$ containing BDT of $10 \mathrm{ml}$. The solution was stirred at room temperature for $24 \mathrm{~h}$. After the reaction, the reaction mixtures were poured into a large amount of ice-water with vigorous stirring, and extracted with chloroform. The organic layer was washed with an excess of water at several times, and dried on anhydrous sodium carbonate. The product was concentrated in vacuo to remove solvents, yielding a pale yellow liquid. Since the crude products included monomer, oligomer, polymer, and other impurities, it was purified by fractional distillation $\left(110^{\circ} \mathrm{C} / 8 \mathrm{mmHg}\right.$, lit. $\left.{ }^{20} \mathrm{ca} .60^{\circ} \mathrm{C} / 5 \mathrm{mmHg}\right)$. The distillated DT was further purified by recrystallization from methanol at several times to remove BDT completely. The purity of DT determined by HPLC was $>99.9 \%$ : m.p. $31.0-31.5^{\circ} \mathrm{C}$ (lit. m.p. $32-33,{ }^{21}$ $\left.32^{\circ} \mathrm{C}^{22}\right) ;{ }^{1} \mathrm{HNMR}\left(\mathrm{CDCl}_{3}, 400 \mathrm{MHz}\right) \delta(\mathrm{ppm}) 1.97$ (s, $\mathrm{CH}_{2} \mathrm{CH}_{2} \mathrm{CH}_{2}, 2 \mathrm{H}$ ), 2.85 (s, S- $\mathrm{CH}_{2}-\mathrm{CH}_{2}, 2 \mathrm{H}$ ); ${ }^{13} \mathrm{CNMR} \quad\left(\mathrm{CDCl}_{3}, \quad 100 \mathrm{MHz}\right) \quad \delta \quad(\mathrm{ppm}) \quad 27.7$ $\left(\mathrm{CH}_{2} \mathrm{CH}_{2} \mathrm{CH}_{2}\right), 33.2\left(\mathrm{~S}-\mathrm{CH}_{2}-\mathrm{CH}_{2}\right)$.

\section{Copolymerization}

Copolymerization was carried out in a sealed glass tube. After DT and LPA (total: $c a .1 .0 \mathrm{~g}$ ) were charged, the tube was degassed and sealed under high vacuum. After copolymerization, the tube was opened and the contents in the tube were poured into a large amount of cyclohexane or $n$-hexane to precipitate the copolymer formed. The copolymer was washed well with a large amount of cyclohexane or $n$-hexane, and dried in vacuo at room temperature for overnight. The copolymer yield was determined by gravimetric method.

\section{Network Formation}

The cross-linking reaction of the poly(LPA-co-DT) was carried out in pyridine at room temperature. The calculated amount $\mathrm{Zn}$ (acetate) $)_{2}$ equivalent to the carboxyl acid in the poly(LPA-co-DT) depending on the copolymer composition was added. The reaction proceeded instantly, and the formed precipitant washed well with methanol for several times to isolate the reaction products.

\section{Characterization}

IR spectra were taken by use of a JASCO FT/IR
430 spectrometer. The samples were prepared according to the following procedure: the polymer was dissolved in a THF solvent, and the solution was added onto a $\mathrm{NaBr}$ plate.

DSC measurements were carried out with a SEIKO Instruments Inc. DSC 6200 in a nitrogen stream at a heating and cooling rate of $10^{\circ} \mathrm{C} / \mathrm{min}$. The sample weights for the DSC measurement were approximately $c a .10 \mathrm{mg}$.

TG/DTA measurements were carried out with a SEIKO Instruments Inc. TG/DTA 6200 at a heating rate of $10^{\circ} \mathrm{C} / \mathrm{min}$ in a nitrogen stream. The sample weights for the TG/DTA measurement were approximately $c a .5 \mathrm{mg}$.

\section{RESULTS AND DISCUSSION}

The copolymerization of DT and LPA was carried out to make a copolymer for producing a enough high degree of cross-linking polymer containing polycatenane structure. The results are shown in Table I. The copolymerization of DT and LPA proceeded to give copolymers having random sequences (Poly(DT-co-LPA)). ${ }^{15}$ Although the molecular weights of the resulting polymers determined by GPC measurement are very high, the poly(DT-co-LPA)s are still soluble in common organic solvents such as THF and chloroform regardless of the copolymer compositions. This may be due to that the molecular weight of the poly(DT-co-LPA) is not enough high to reach gel points. We then examined the formation of a enough high degree of cross-linking using attached acid groups of the side chain in the LPA units with $\mathrm{Zn}$ (acetate $)_{2}$ as a cross-linking reagent. ${ }^{17}$

When $\mathrm{Zn}$ (acetate) $)_{2}$ was added to the poly(LPA-coDT) in pyridine at room temperature, the insoluble product was formed instantly. The change of solubility between the poly(LPA-co-DT) and the reaction product is shown in Table II. It is clear that the reaction product regardless of the copolymer composition did not dissolved in all common organic solvents examined. This suggests that the cross-linking reaction took place between $\mathrm{Zn}^{2+}$ and two acid groups attach-

Table I. Copolymerization DT with LPA in bulk at $80^{\circ} \mathrm{C}$ for $6 \mathrm{~h}$

\begin{tabular}{ccccc}
\hline $\begin{array}{c}\text { [LPA] in } \\
\begin{array}{c}\text { comonomer } \\
(\mathrm{mol} \%)\end{array}\end{array}$ & $\begin{array}{c}\text { Polymer yield } \\
(\%)\end{array}$ & $\begin{array}{c}{[\mathrm{LPA}] \text { in }} \\
\text { copolymer } \\
(\mathrm{mol} \%)\end{array}$ & $\left.M_{\mathrm{n}} \times 10^{-4} \mathrm{a}\right)$ & $M_{\mathrm{w}} / M_{\mathrm{n}}{ }^{\mathrm{a})}$ \\
\hline 100 & 80.3 & 100.0 & 41.6 & 2.35 \\
30.0 & 58.0 & 37.6 & 20.1 & 1.45 \\
10.0 & 47.9 & 10.2 & $-{ }^{\mathrm{b})}$ & - - $^{\mathrm{b}}$ \\
3.0 & 31.5 & 3.0 & $\left.-{ }^{\mathrm{b}}\right)$ & $\left.-{ }^{\mathrm{b}}\right)$ \\
0 & 35.8 & 0.0 & 16.8 & 1.43 \\
\hline
\end{tabular}

a) Determined by GPC. b) Not determined. 
Table II. The solubility changes of poly(LPA-co-DT)s by the crosslinking reaction with $\mathrm{Zn}(\text { acetate })_{2}{ }^{\text {a) }}$

\begin{tabular}{|c|c|c|c|c|c|c|c|c|}
\hline \multirow{2}{*}{$\begin{array}{c}\text { [LPA] } \\
\text { in } \\
\text { copolymer }\end{array}$} & \multicolumn{2}{|c|}{ THF } & \multicolumn{2}{|c|}{$\mathrm{CHCl}_{3}$} & \multicolumn{2}{|c|}{ DMF } & \multicolumn{2}{|c|}{ Pyridine } \\
\hline & A & B & A & B & A & B & $\mathrm{A}$ & B \\
\hline 37.6 & Sol & Insol & Insol & Insol & Swell & Insol & Sol & Insol \\
\hline 10.2 & Sol & Insol & Insol & Insol & Insol & Insol & Sol & Insol \\
\hline 3.0 & Sol & Insol & Sol & Insol & Insol & Insol & Sol & Insol \\
\hline
\end{tabular}

a) Reacted at room temperature. Sol: Soluble, Insol.: Insoluble, A: poly(LPA-co-DT), B: Croslinking reaction product.

ed to the polycatenane structure to give a enough high degree of cross-linking structure as shown in Scheme 2.

To confirm the enough high degree of cross-linking formation, the reaction product was analyzed by IR spectroscopy. Figure 1 shows the typical IR spectra of the poly(LPA-co-DT) and the reaction product. In the reaction product, the peaks at 1710,1410 and $1300-1200 \mathrm{~cm}^{-1}$ based on the carboxyl acid group of LPA unit in the poly(LPA-co-DT) completely disappeared, and new peaks at 1600 and $1400 \mathrm{~cm}^{-1}$ based on the carboxylate anion appeared. This indicates that the metal ionomeric network between the acid groups of LPA units in the copolymer and $\mathrm{Zn}^{2+}$ ion of $\mathrm{Zn}$ (acetate) $)_{2}$ was formed to give the enough high degree of cross-linking structure as shown in Scheme 2.

To elucidate further the structure of the cross-linked product, thermal analysis of the products was examined. The DSC charts of the poly(LPA-co-DT) and the cross-linked product are shown in Figure 2. In the copolymer containing $3 \mathrm{~mol} \%$ LPA units, the glass transition temperature $\left(T_{\mathrm{g}}\right)$ and the melting point $\left(T_{\mathrm{m}}\right)$ were observed even after the croslinking reaction of the poly(LPA-co-DT) with $\mathrm{Zn}$ (acetate $)_{2}$. On the other hand, in the copolymer containing $37.6 \mathrm{~mol} \%$ LPA units, the $T_{\mathrm{g}}$ of the cross-linked copolymer was observed, but the $T_{\mathrm{m}}$ of the cross-linked copolymer

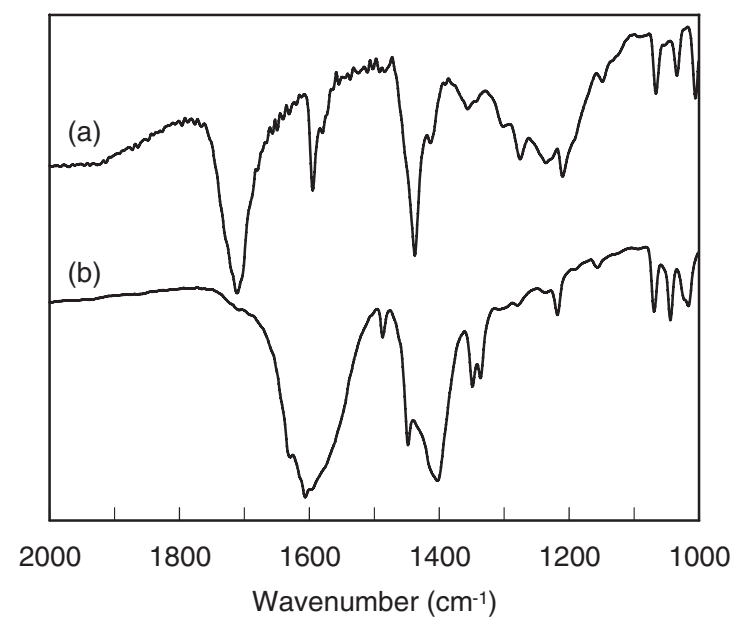

Figure 1. IR spectra of (a) poly(LPA-co-DT) and (b) the cross-linked copolymer reacted with $\mathrm{Zn}(\text { acetate })_{2}$.

was not observed. This may be explained by that the increase of cross-linking density make it impossible to crystallize the reaction product by decreasing mobility of the polycatenane moiety.

The data of the $T_{\mathrm{g}}$ and $T_{\mathrm{m}}$ of the copolymer determined by the DSC are listed in Table III. It is clear that the $T_{\mathrm{g}}$ was shifted to higher temperature after the cross-linking reaction, and the $T_{\mathrm{g}}$ of the product depend on LPA content in the copolymer. On the other hand, the $T_{\mathrm{m}}$ of the cross-linked copolymers was the almost same as that of the precursor copolymer. Interestingly, the $T_{\mathrm{m}}$ was observed clearly in the cross-linked copolymers consisting of LPA contents of 3.0 and $10 \mathrm{~mol} \%$. Generally, it is difficult to observe the $T_{\mathrm{m}}$ for cross-linked polymers for its low mobility of the chain. Thus, the results demonstrate that the enough high degree of cross-linking structure should contain the polycatenane structure as shown in Scheme 2. Namely, the behavior on the $T_{\mathrm{m}}$ of the materials supports that polycatenane structure even in the enough high degree of cross-linking product.
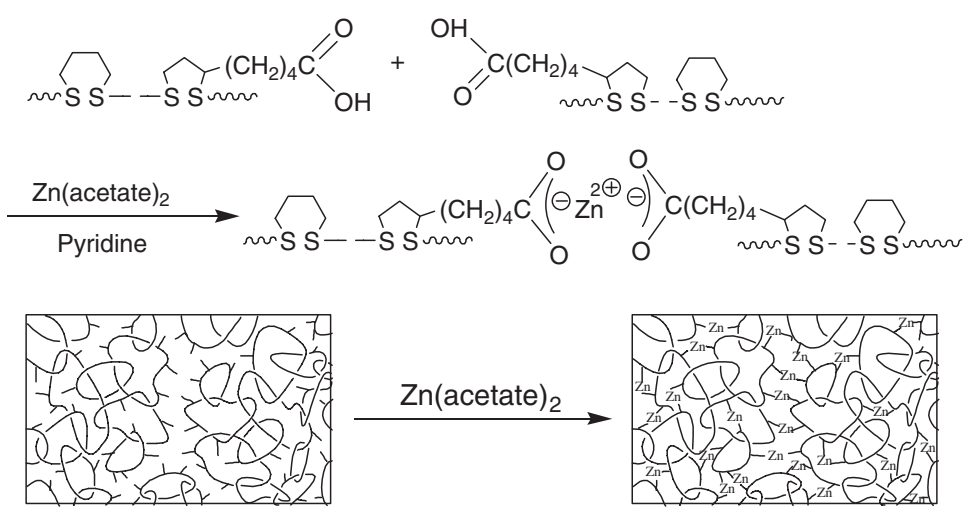

Scheme 2. Reaction of poly(LPA-co-DT) with $\mathrm{Zn}(\text { acetate })_{2}$. 


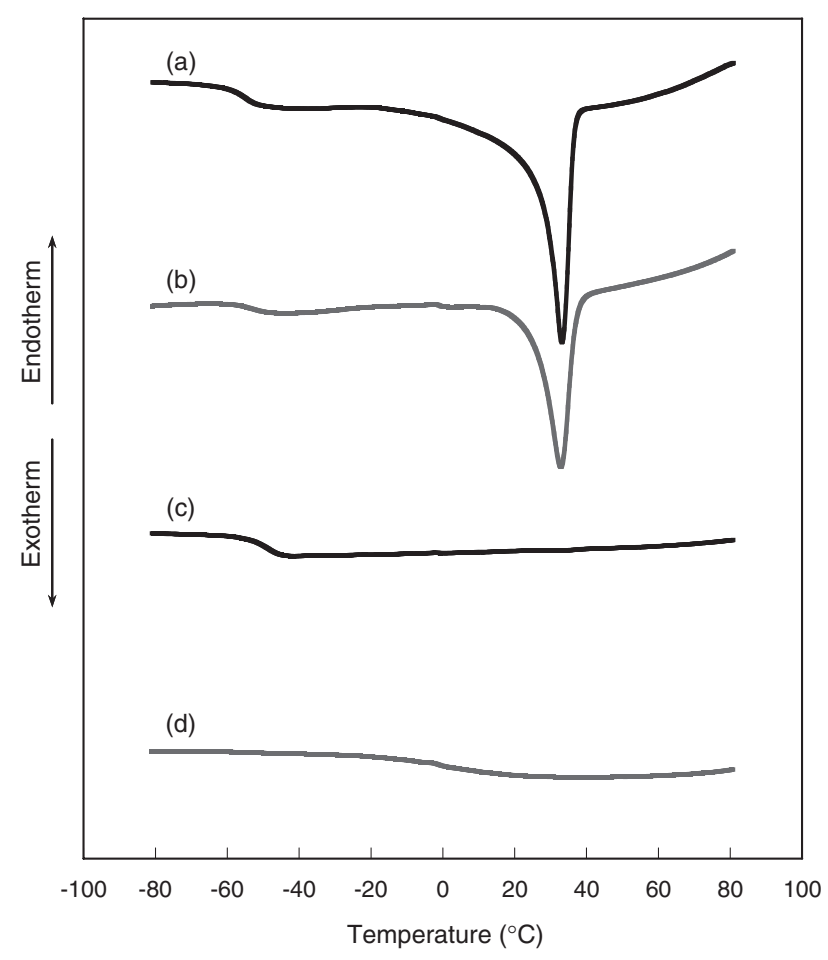

Figure 2. DSC curves of poly(LPA-co-DT) ([LPA] in copolymer are $3 \mathrm{~mol} \%$ ( $\mathrm{a}$ and $\mathrm{c}$ ) and $37.6 \mathrm{~mol} \%$ (b and d)). The charts of (a) and (b) are before the cross-linking reaction copolymer, and the charts of (c) and (d) are after the cross-linking reaction product at a heating rate of $10^{\circ} \mathrm{C} / \mathrm{min}$ in a nitorgen stream.

Table III. Thermal properties of poly(LPA-co-DT) and the cross-linked product with $\mathrm{Zn}(\text { acetate })_{2}{ }^{\mathrm{a})}$

\begin{tabular}{|c|c|c|c|c|}
\hline \multirow[b]{2}{*}{$\begin{array}{l}{[\mathrm{LPA}] \text { in }} \\
\text { copolymer } \\
(\mathrm{mol} \%)\end{array}$} & \multicolumn{2}{|c|}{$T_{\mathrm{m}}\left({ }^{\circ} \mathrm{C}\right)$} & \multicolumn{2}{|c|}{$T_{\mathrm{g}}\left({ }^{\circ} \mathrm{C}\right)$} \\
\hline & $\begin{array}{c}\text { Poly- } \\
\text { (LPA-co- } \\
\text { DT) }\end{array}$ & $\begin{array}{c}\text { Cross- } \\
\text { linked } \\
\text { Product }\end{array}$ & $\begin{array}{c}\text { poly- } \\
\text { (LPA-co- } \\
\text { DT) }\end{array}$ & $\begin{array}{l}\text { Cross- } \\
\text { linked } \\
\text { Product }\end{array}$ \\
\hline 100.0 & -b) & -c) $^{\mathrm{c}}$ & -37.0 & -c) \\
\hline 37.6 & -b) $^{\text {b }}$ & -b) $^{\text {b }}$ & -49.6 & 2.1 \\
\hline 10.2 & 30.0 & 36.5 & -53.3 & -48.2 \\
\hline 3.0 & 33.1 & 32.8 & -54.8 & -52.2 \\
\hline 0.0 & 41.5 & - & -55.6 & - \\
\hline
\end{tabular}

a) $T_{\mathrm{m}}$ and $T_{\mathrm{g}}$ were determined by DSC at a heating rate of $10^{\circ} \mathrm{C} / \mathrm{min}$ in a nitrogen stream. b) Not observed. c) Crosslinked reaction was not carried out.

The TGA analysis of the cross-linked product was also examined to elucidate the thermal stability of the cross-linked product. The charts are shown in Figure 3, and the data obtained from the charts are listed in Table IV. The initial decomposition temperature of the sample $\left(T_{\text {ini }}\right)$ determined by TG/DTA was higher than those of the poly(LPA-co-DT)s. The residual of the samples at $490^{\circ} \mathrm{C}$ was not observed for the poly(LPA-co-DT), but all cross-linked samples examined gave the residue at $490^{\circ} \mathrm{C}$, and the residue at $490^{\circ} \mathrm{C}$ increased with an increase of LPA unit in the copolymer. This indicates that the cross-linked

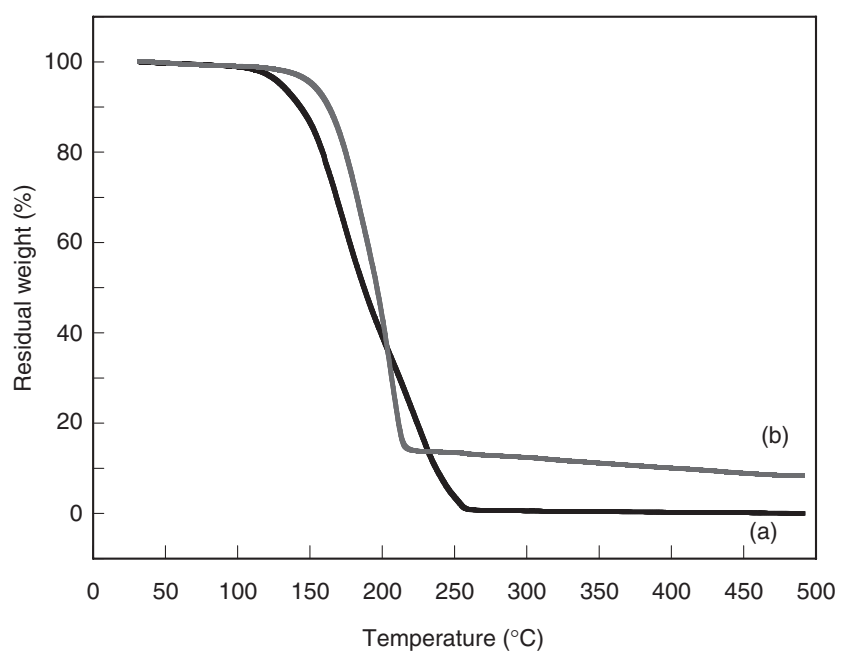

Figure 3. TG curves of (a) poly(LPA-co-DT) ([LPA] is 3.0 mol $\%$ in the copolymer) and (b) its cross-linked copolymer by $\mathrm{Zn}$ (acetate $)_{2}$ at a heating rate of $10^{\circ} \mathrm{C} / \mathrm{min}$ in a nitorgen stream.

Table IV. TGA data for the poly(LPA-co-DT) and the cross-linked product with $\mathrm{Zn}(\text { acetate })_{2}{ }^{\text {a) }}$

\begin{tabular}{|c|c|c|c|c|}
\hline \multirow{2}{*}{$\begin{array}{c}{[\mathrm{LPA}] \text { in }} \\
\text { Copolymer } \\
(\mathrm{mol} \%)\end{array}$} & \multicolumn{2}{|c|}{$T_{\text {ini }}\left({ }^{\circ} \mathrm{C}\right)$} & \multicolumn{2}{|c|}{$\begin{array}{l}\text { Residual weight } \\
\text { at } 490^{\circ} \mathrm{C} \text { (wt \%) }\end{array}$} \\
\hline & $\begin{array}{c}\text { Poly- } \\
\text { (LPA-co- } \\
\text { DT) }\end{array}$ & $\begin{array}{c}\text { Cross- } \\
\text { linked } \\
\text { Product }\end{array}$ & $\begin{array}{c}\text { Poly- } \\
\text { (LPA-co- } \\
\text { DT) }\end{array}$ & $\begin{array}{l}\text { Cross- } \\
\text { linked } \\
\text { Product }\end{array}$ \\
\hline 100.0 & - & 96.8 & - & 0.0 \\
\hline 37.6 & 101.8 & 107.4 & 0.0 & 14.3 \\
\hline 10.2 & 106.8 & 122.5 & 0.0 & 8.7 \\
\hline 3.0 & 105.8 & 106.0 & 0.1 & 8.4 \\
\hline 0.0 & - & 127.7 & - & 0.0 \\
\hline
\end{tabular}

a) Determined by TGA at a heating rate of $10^{\circ} \mathrm{C} / \mathrm{min}$ in a nitrogen stream.

product consists of the ionomeric structure. Taking the amounts of the residue at $490^{\circ} \mathrm{C}$ of the samples into consideration, the presence of non-reacted $\mathrm{Zn}(\text { acetate })_{2}$ in the product may be speculated.

\section{REFERENCES}

1. T. McLeish, Science, 297, 2005 (2002).

2. C. W. Bielawski, D. Benitez, and R. H. Grubbs, Science, 297, 2041 (2002).

3. C. W. Bielawski, D. Benitez, and R. H. Grubbs, J. Am. Chem. Soc., 125, 8424 (2003).

4. K. A. Alberty, E. Tillman, S. Carlotti, K. King, S. E. Bradforth, T. E. Hogen-Esch, D. Parker, and W. J. Feast, Macromolecules, 35, 3856 (2002).

5. H. Iatrou, N. Hadjichristidis, G. Meier, H. Frielinghaus, and M. Monkenbusch, Macromolecules, 35, 5426 (2002).

6. Y. Tezuka and H. Oike, J. Am. Chem. Soc., 123, 11570 (2001).

7. Y. Tezuka and H. Oike, Prog. Polym. Sci., 27, 1069 (2002).

8. P. Rempp, C. Strazielle, and P. Lutz, in "Encyclopedia of 
Polymer Science and Engineering,” 2nd ed., J. I. Kroschwitz Ed., Wiley, New York, 1987, Vol. 9, pp 183-195.

9. K. Endo, T. Shiroi, N. Murata, G. Kojima, and T. Yamanaka, Macromolecules, 37, 3143 (2004).

10. K. Endo, T. Shiroi, and N. Murata, Polym. J., 37, 512 (2005).

11. K. Endo, G. Kojima, and T. Yamanaka, Kautsch. Gummi Kunstst., 59, 41 (2006).

12. Y. Okumura and K. Ito, Adv. Mater., 13, 485 (2001).

13. H. Oike, T. Mouri, and Y. Tezuka, Macromolecules, 34,
6229 (2001).

14. N. Watanabe, Y. Ikari, N. Kihara, and T. Takata, Macromolecules, 37, 6663 (2004).

15. K. Endo and T. Yamanaka, Marcromolecules, 39, 4038 (2006).

16. R. Singh and G. M. Whitesides, J. Am. Chem. Soc., 112, 6304 (1990).

17. L. Leibler, M. Rubinstein, and R. H. Colby, Macromolecules, 24, 4701 (1991). 